\title{
The association between maternal use of folic acid supplements during pregnancy and risk of autism spectrum disorders in children: a meta-analysis
}

\author{
Meiyun Wang ${ }^{1}$, Kaiqin $\mathrm{Li}^{2}$, Dongmei Zhao ${ }^{1}$ and Ling $\mathrm{Li}^{1^{*}}$
}

\begin{abstract}
Previous reviews have been conducted to evaluate the association between maternal use of folic acid supplements during pregnancy and risk of autism spectrum disorders (ASD) in children, with no definitive conclusion. We therefore conducted a more comprehensive meta-analysis to reassess the relationship between folic acid and the risk of ASD. The electronic databases PubMed, Web of Knowledge, and Wanfang Data were carefully searched to find eligible studies as recent as March 2017. A random effects model was used to combine the relative risk (RR) with 95\% confidence intervals (CI). Sensitivity analysis and publication bias were conducted. A total of 12 articles with 16 studies comprising 4514 ASD cases were included in this report. It was found that supplementation with folic acid during pregnancy could reduce the risk of $A S D\left[R R=0.771,95 \% \mathrm{Cl}=0.641-0.928, P^{2}=59.7 \%\right.$, $\left.P_{\text {heterogeneity }}=0.001\right]$ as compared to those women without folic acid supplementation. The associations were significant among Asian, European, and American populations. In summary, this comprehensive meta-analysis suggested that maternal use of folic acid supplements during pregnancy could significantly reduce the risk of ASD in children regardless of ethnicity, as compared to those women who did not supplement with folic acid.
\end{abstract}

Keywords: Maternal, Folic acid supplements, Autism spectrum disorders, Children, Meta-analysis

We began our exploration into this topic through a study entitled "Environmental risk factors for autism: an evidence-based review of systematic reviews and metaanalyses" [1]. Within that paper, the authors analyzed the environmental risk factors for autism, including maternal use of folic acid supplements during pregnancy. Additionally, a study had been conducted to assess the association between folic acid and autism, which investigated that specific relationship more thoroughly [2]. However, these two previous studies did not combine their results using a meta-analytic approach. Therefore, the aim of this article is to establish a more definitive conclusion on the association between maternal use of folic acid supplements during pregnancy and autism spectrum disorder (ASD) risk in children.

\footnotetext{
*Correspondence: ling_li2017@yeah.net

'Department of Pediatric Health Care, Ji'nan Children's Hospital of Shandong University, No. 23976, Jingshi Road, Ji'nan, Shandong Province 250022, China Full list of author information is available at the end of the article
}

The databases of PubMed, Web of Knowledge, and Wanfang Database were searched extensively to find eligible studies as recent as March 2017. The following search terms were used: ["folate" OR "folic acid" OR "vitamins" OR "diet"] AND ["Autism" OR "Autism spectrum disorder" OR "ASD"]. Articles were included if they presented data regarding the association between folic acid supplements during pregnancy and risk for ASD. Studies were excluded if they were written in languages other than English and Chinese, did not offer enough data, were reviews, editorials, comments, or if the studies were not conducted with humans as the test subjects. Two independent investigators searched and reviewed all identified studies, then extracted the data reported in Additional file 1: Table S1.

The DerSimonian and Laird random effects model was adopted to pool the study-specific relative risk (RR) with their 95\% confidence intervals (CI) on the association between maternal use of folic acid supplements 
during pregnancy and ASD risk, which considers both within-study and between-study variation [3]. Heterogeneity across studies was checked by the chi-square test and $I^{2}$ test, and $I^{2}$ values of $0,25,50$, and $75 \%$ represent no, low, moderate, and high heterogeneity, respectively $[4,5]$. Sensitivity analysis was performed to assess whether the results could be affected markedly when one study was removed at a time [6]. Small study effect was assessed with visual inspection of Egger's test and funnel plot [7]. Data was analyzed using STATA version 12.0 (Stata Corporation, College Station, TX, USA). $P \leq 0.05$ (two-tailed) was accepted as statistically significant for computed effects.

The flowchart of this meta-analysis for exclusion/inclusion of studies is shown in Additional file 2: Figure S1. A total of 12 articles [8-19] with 16 studies comprising 4514 ASD cases were included in this report. Overall, maternal use of folic acid supplements during pregnancy could reduce the risk of ASD $[\mathrm{RR}=0.771,95 \% \mathrm{CI}=0.641$ $0.928, I^{2}=59.7 \%, P_{\text {heterogeneity }}=0.001$, Fig. 1$]$ as compared to those with no folic acid supplementation. Inverse relationships were found both in prospective studies $[R R=0.903,95 \% \mathrm{CI}=0.786-0.998]$ and in case-control studies $[\mathrm{RR}=0.435,95 \% \mathrm{CI}=0.264-0.717]$. The associations were also significant among Asian populations $[R R=0.669,95 \% C I=0.461-0.972]$, European populations $[\mathrm{RR}=0.844,95 \% \mathrm{CI}=0.683-0.993]$, and American populations $[R R=0.405,95 \% \mathrm{CI}=0.165-0.994]$ (Fig. 1). The detailed subgroup analyses are showed in Table 1.
In the pooled result for all of the studies included, evidence of between-study heterogeneity was demonstrated. We therefore used univariate meta-regression to explore the reason for this high heterogeneity with the covariates of publication year, number of cases, study type, the time of folic acid supplement intake, the method of folic acid supplementation, and geographic locations. No significant finding was found contributing significantly to the between-study heterogeneity. Begg's funnel plot (Additional file 3: Figure S2) and Egger's test $(P=0.112)$ indicated that there was no significant publication bias. Sensitivity analysis showed that no single study had excessive influence on the pooled result while excluding one study at a time (Additional file 4: Figure S3).

One limitation of our report is that mothers were asked to recall a period several years before the interview when reporting on folic acid and supplement information. Given the elapsed time of the period of recall, inaccuracies would be expected. Another limitation is the significant heterogeneity observed in the result. The between-study heterogeneity was not resolved by metaregression, and the results of subgroup analyses also demonstrated high heterogeneity. Therefore, other genetic and environment variables, as well as their possible interactions, may be potential contributors to the heterogeneity found.

In summary, this comprehensive meta-analysis suggested that maternal use of folic acid supplements during pregnancy could significantly reduce the risk of ASD

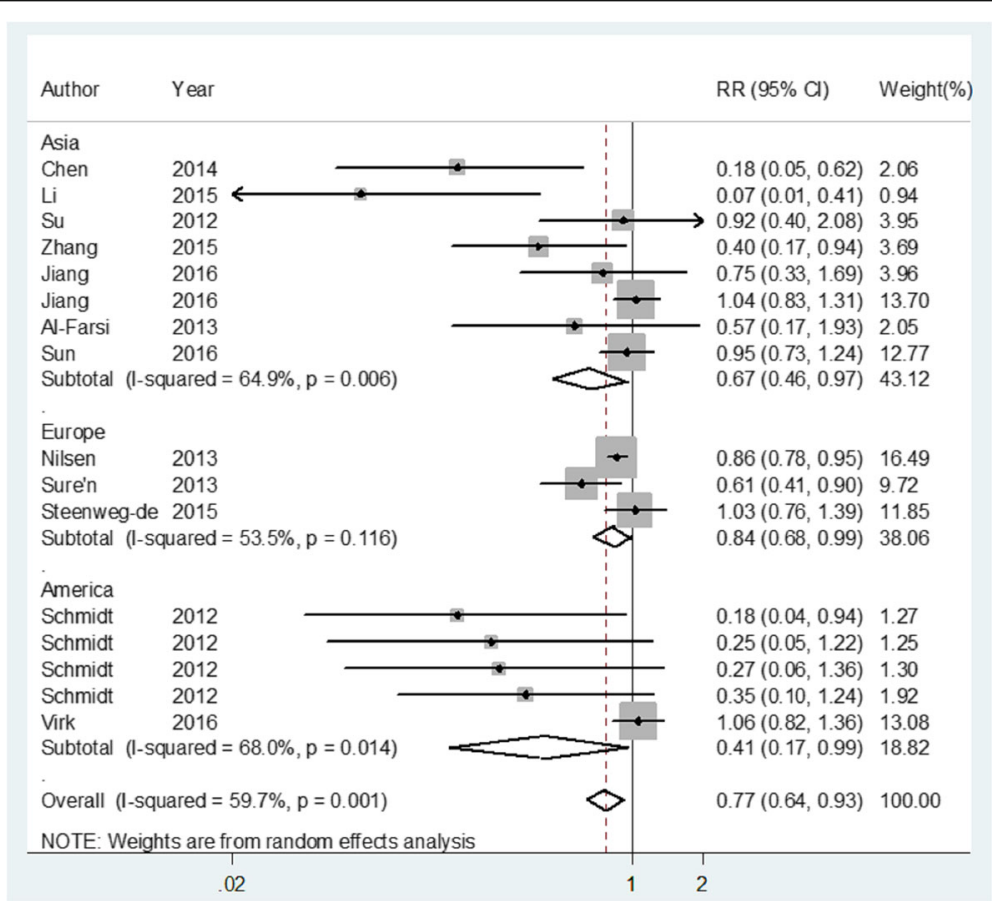

Fig. 1 The forest plot of the association between maternal use of folic acid supplements during pregnancy compared with those no supplements, subgroup by ethnicity 
Table 1 Summary risk estimates of the overall and subgroup analyses on maternal use of folic acid supplements during pregnancy and risk of autism spectrum disorders in children

\begin{tabular}{|c|c|c|c|c|c|}
\hline \multirow{2}{*}{$\begin{array}{l}\text { Subgroups } \\
\text { All studies }\end{array}$} & \multirow{2}{*}{$\frac{\text { No. (cases) }}{4514}$} & \multirow{2}{*}{$\frac{\text { No. (studies) }}{16}$} & \multirow{2}{*}{$\begin{array}{l}\text { Risk estimate }(95 \% \mathrm{Cl}) \\
0.771(0.641-0.928)\end{array}$} & \multicolumn{2}{|c|}{ Heterogeneity test $P^{2}$ (\%) $P$ value } \\
\hline & & & & 59.7 & 0.001 \\
\hline \multicolumn{6}{|l|}{ Study design } \\
\hline Prospective & 2794 & 5 & 0.903(0.786-0.998) & 42.6 & 0.138 \\
\hline Case-control & 1720 & 11 & $0.435(0.264-0.717)$ & 66.0 & 0.001 \\
\hline \multicolumn{6}{|l|}{ Ethnicity } \\
\hline Asian & 1581 & 8 & $0.669(0.461-0.972)$ & 64.9 & 0.006 \\
\hline European & 2258 & 3 & 0.844(0.683-0.993) & 53.5 & 0.116 \\
\hline American & 675 & 5 & 0.405(0.165-0.994) & 68.0 & 0.014 \\
\hline
\end{tabular}

in children as compared to those without folic acid supplementation. Significant associations were found in Asian, European, and American populations. Since some limitations are present in our study, future studies should aim to investigate the effect of the timing of folic acid supplement intake during the pregnancy, as well as the effects of varying dosages.

\section{Additional files}

Additional file 1: Table S1. Characteristics of the included studies on maternal use of folic acid supplements during pregnancy and risk of autism spectrum disorders in children. (DOC $49 \mathrm{~kb}$ )

Additional file 2: Figure S1. Flowchart of study selection. (TIFF $102 \mathrm{~kb}$ )

Additional file 3: Figure S2. Begg's funnel plot of the association between maternal use of folic acid supplements during pregnancy compared with those no supplements. (TIFF $116 \mathrm{~kb}$ )

Additional file 4: Figure S3. Sensitivity analysis of the association between maternal use of folic acid supplements during pregnancy compared with those no supplements. (TIFF 8 kb)

\section{Abbreviations}

ASD: Autism spectrum disorders; $\mathrm{Cl}$ : Confidence intervals; RR: Relative risk

\section{Acknowledgements}

We thank Nicholas J Clayton for his assistance with the English grammar editing.

\section{Funding}

None

\section{Availability of data and materials}

All data relevant to the manuscript are presented in the manuscript.

\section{Authors' contributions}

MYW conceived of the study; MYW, DMZ, and LL carried out the literature searching; MYW, DMZ, and LL extracted the data; MYW analyzed the data; $M Y W, K Q L$, and $L L$ drafted and reviewed the manuscript. All authors read and approved the final manuscript.

\section{Ethics approval and consent to participate}

Not applicable

\section{Consent for publication}

All the authors consented for publication.

\section{Competing interests}

The authors declare that they have no competing interests.

\section{Publisher's Note}

Springer Nature remains neutral with regard to jurisdictional claims in published maps and institutional affiliations.

\section{Author details}

${ }^{1}$ Department of Pediatric Health Care, Ji'nan Children's Hospital of Shandong University, No. 23976, Jingshi Road, Ji'nan, Shandong Province 250022, China. ${ }^{2}$ Department of Gynecology, The Central Hospital of Linyi City, Linyi, Shandong 276000, China.

Received: 29 May 2017 Accepted: 22 September 2017

Published online: 02 October 2017

\section{References}

1. Modabbernia A, Velthorst E, Reichenberg A. Environmental risk factors for autism: an evidence-based review of systematic reviews and meta-analyses. Mol Autism. 2017:8(13):1-16.

2. Castro K, Klein Lda S, Baronio D, Gottfried C, Riesgo R, Perry IS. Folic acid and autism: what do we know? Nutr Neurosci. 2016;19(7):310-7.

3. DerSimonian R, Laird N. Meta-analysis in clinical trials. Control Clin Trials. 1986;7(3):177-88.

4. Higgins JP, Thompson SG. Quantifying heterogeneity in a meta-analysis. Stat Med. 2002;21(11):1539-58.

5. Higgins JP, Thompson SG, Deeks JJ, Altman DG. Measuring inconsistency in meta-analyses. BMJ. 2003:327(7414):557-60.

6. Tobias A. Assessing the in fluence of a single study in the meta-analysis estimate. Stata Tech Bull. 1999:47(9):15-7.

7. Egger M, Davey Smith G, Schneider M, Minder C. Bias in meta-analysis detected by a simple, graphical test. BMJ. 1997:315(7109):629-34.

8. Chen Q, Huang LX, Xu WJ, Chen H, Zhong JQ, Zeng CX. Research on the prevalence and the risk factors of autism spectrum disorder from 1.5 to 3 years old in Zhuhai city. CJCHC. 2014;22(6):649-51.

9. Li X, Ling ZY, Wang JM, Yang SP, Tan YY, Xie SN, et al. Periconceptional risk factors for childhood autism: a 1:1 matched case-control study. Acta Med Univ Sci Technol Huazhong. 2015;44(3):357-61.

10. Su YY and Zhang XX. Effect of environmental risk factor on children with autistic disorder and mental retardation. 2012.

11. Gao $L$ and Zhang $X$. The study of early risk factors and early manifestation of autism spectrum disorder (ASD). 2015.

12. Jiang $H$, Liu L, Sun DL, Yin XN, Chen ZD, Wu CA, et al. Interaction between passive smoking and folic acid supplement during pregnancy on autism spectrum disorder behaviors in children aged 3 years. Chin J Epidemiol. 2016;37(7):940-4.

13. Al-Farsi YM, Waly MI, Deth RC, Al-Sharbati MM, Al-Shafaee M, Al-Farsi O, et al. Low folate and vitamin B12 nourishment is common in Omani children with newly diagnosed autism. Nutrition. 2013;29(3):537-41.

14. Sun YL, Shao T, Yao YY, Tao HH, Ni LL, Yan SQ, et al. Pregnancy-related anxiety and subthreshold autism trait in preschool children based a birth cohort study. Chin J Prev Med. 2016:50(2):118-22.

15. Nilsen RM, Suren P, Gunnes N, Alsaker ER, Bresnahan M, Hirtz D, et al. Analysis of self-selection bias in a population-based cohort study of autism spectrum disorders. Paediatr Perinat Epidemiol. 2013;27(6):553-63. 
16. Suren P, Roth C, Bresnahan M, Haugen M, Hornig M, Hirtz D, et al. Association between maternal use of folic acid supplements and risk of autism spectrum disorders in children. JAMA. 2013;309(6):570-7.

17. Steenweg-de Graaff J, Ghassabian A, Jaddoe WW, Tiemeier H, Roza SJ. Folate concentrations during pregnancy and autistic traits in the offspring. The Generation R Study. Eur J Pub Health. 2015;25(3):431-3.

18. Schmidt RJ, Tancredi DJ, Ozonoff S, Hansen RL, Hartiala J, Allayee H, et al. Maternal periconceptional folic acid intake and risk of autism spectrum disorders and developmental delay in the CHARGE (CHildhood Autism Risks from Genetics and Environment) case-control study. Am J Clin Nutr. 2012; 96(1):80-9.

19. Virk J, Liew Z, Olsen J, Nohr EA, Catov JM, Ritz B. Preconceptional and prenatal supplementary folic acid and multivitamin intake and autism spectrum disorders. Autism. 2016;20(6):710-8.

Submit your next manuscript to BioMed Central and we will help you at every step:

- We accept pre-submission inquiries

- Our selector tool helps you to find the most relevant journal

- We provide round the clock customer support

- Convenient online submission

- Thorough peer review

- Inclusion in PubMed and all major indexing services

- Maximum visibility for your research

Submit your manuscript at www.biomedcentral.com/submit
Biomed Central 